\title{
Does Touch Affect Taste? The Perceptual Transfer of Product Container Haptic Cues
}

\author{
ARADHNA KRISHNA \\ MAUREEN MORRIN*
}

\begin{abstract}
We develop a conceptual framework regarding the perceptual transfer of haptic or touch-related characteristics from product containers to judgments of the products themselves. Thus, the firmness of a cup in which water is served may affect consumers' judgments of the water itself. This framework predicts that not all consumers are equally affected by such nondiagnostic haptic cues. Results from four studies show that consumers high in the autotelic need for touch (general liking for haptic input) are less affected by such nondiagnostic haptic cues compared to consumers low in the autotelic need for touch. The research has many implications for product and package design.
\end{abstract}

$\mathrm{D}$ oes food served on a paper plate taste worse than the same food served on a china plate? Does mineral water served in a flimsy cup taste worse than the same water served in a firmer cup? Although the paper plate and flimsy cup may be less aesthetically appealing to a consumer, rationally speaking, the product containers should not affect the actual quality or taste of the products within those containers. Nevertheless, in this article we develop a conceptual framework that posits that haptic or touch-related characteristics of product containers may indeed be transferred to the products contained therein through consumer inferences and evaluations. This framework also predicts that not all consumers are equally affected by such irrelevant or nondiagnostic haptic cues from product containers. Rather, we propose that haptically oriented individuals, or those who tend to enjoy touching products, will be less affected by such cues because of their heightened awareness of and ability to correct for the potential impact of such cues.

Prior research has shown that the mere act of interpersonal touching affects behavioral compliance and reciprocation in many consumer contexts. For instance, Crusco and Wetzel

*Aradhna Krishna is the Isadore and Leon Winkelman Professor of Marketing at the Ross School of Business, University of Michigan, 701 Tappan Street, Ann Arbor, MI 48109-1234 (aradhna@umich.edu). Maureen Morrin is associate professor of marketing, Rutgers University, 227 Penn Street, Camden, NJ 08102 (mmorrin@ rutgers.edu). Author names are in alphabetical order. Correspondence: Aradhna Krishna. The authors would like to thank Fengxia Fang, May Lwin, and Catherine Yeung for their help in data collection, and Julie Ruth for her many helpful suggestions on earlier drafts. Much of the work for this article was done while the first author was visiting the National University of Singapore.

John Deighton served as editor and Laura Peracchio served as associate editor for this article.

Electronically published October 17, 2007
(1984) showed that being touched by a waiter in a restaurant increases tips. Hornik (1992) showed that consumers touched by a requester (to taste a new snack in a supermarket) tend to comply more than customers in a no-touch situation. In a similar vein, Hornik and Ellis (1988) showed that interpersonal touch increases shoppers' willingness to take part in mall intercept interviews.

Other research has explored how the act of touching products affects consumer response. McDaniel and Baker (1977) showed, for example, that a negative packaging attribute can sometimes lead to higher product quality evaluations. They found that potato chips in polyvinyl (vs. wax-coated) bags, which were harder to open, led consumers to believe the chips tasted better. It could be that harder-to-open bags were seen as sealing in the freshness of the chips and hence were diagnostic for product evaluation. In a study looking at touch by others, Argo, Dahl, and Morales (2006) showed that consumers react negatively if they believe products have already been touched by others. Peck and Childers (2003a, 2003b) demonstrated the importance of individual-level differences in haptic orientation or preference for productbased haptic information.

Thus, the effect of the perceived haptic properties of products would appear to have significant implications for consumer behavior. Research in this emerging area has concentrated primarily on touch versus no-touch conditions, rather than manipulating the quality of the touch-related input (McDaniel and Baker 1977). Moreover, research in this area has typically focused on contexts in which the haptic information is diagnostic for the target task - that is, when it provides objective information relevant to product judgment, such as touching a sweater to assess its thickness or texture (Peck and Childers 2003a).

In the current research we embark on a different direction 
by focusing on the effects of the quality of nondiagnostic haptic input on product evaluation. We propose a framework that outlines how the haptic effects will differ according to the individual's haptic orientation. To clarify, by nondiagnostic haptic cues we mean those that are not objectively relevant to the judgment task. For example, the fact that a beverage container feels flimsy to the touch should not affect the actual taste or quality of the beverage itself and thus would be considered a negatively valenced nondiagnostic haptic cue in the proposed framework.

Previous work has demonstrated the considerable effects that irrelevant or nondiagnostic information can have on consumer judgments (Broniarczyk and Gershoff 1997, 2003; Meyvis and Janiszewski 2002; Shiv, Carmon, and Ariely 2005; Simonson, Nowlis, and Simonson 1993; van Osselaer, Alba, and Manchanda 2004). Researchers to date, however, have left largely unexplored the impact of nondiagnostic cues in the domain of touch and the moderating effect of haptic orientation. Peck and Childers (2003a, 440) have noted the lack of research on the relationship between individual differences in haptic orientation and "whether this facilitates or inhibits the utilization of information available through other forms of input. It is not clear . . . whether haptic forms of information might differentially affect (either facilitate or inhibit) the use of other perceptual sensebased forms of information." The current research seeks to fill this void by suggesting how individual differences in haptic orientation moderate the use of nondiagnostic haptic cues in taste judgment.

\section{RESEARCH ON HAPTICS AND THE NEED-FOR-TOUCH SCALE}

Interest in the topic of haptics and consumers' orientation toward the sense of touch has grown in recent years. The term "haptic perception" implies "perceptual processing of inputs from multiple subsystems including those in skin, muscles, tendons and joints" (Wolfe, Kluender, and Levi 2006, 303). We focus more specifically on touch by hand. Recent research has demonstrated that individual consumers differ in terms of their haptic orientation, or need for touch (NFT), which is conceptually defined as "a preference for the extraction and utilization of information obtained through the haptic system" (Peck and Childers 2003a, 431). Haptic orientation is thus an individual difference variable that reflects a person's motivation to or preference for touch. Those with a higher NFT have been shown to be more confident in their product judgments when they are able to touch the products they evaluate, and they are more frustrated when they are not permitted to touch products (Peck and Childers 2003b).

Similar to the need-for-cognition (Cacioppo and Petty 1982) and need-to-evaluate (Jarvis and Petty 1996) scales, the need-for-touch scale does not assume a biological basis for this individual difference. Instead, the researchers propose a dual-motivation model (McClelland, Koestner, and Weinberger 1989) in which NFT is conceptualized as a construct with two underlying dimensions: instrumental and autotelic. The instrumental dimension of NFT reflects analytic thought that is initiated by an explicit goal that drives behavior, typically a purchase goal (e.g., "the only way to make sure a product is worth buying is to actually touch it"). Thus, it is motivation driven. The autotelic dimension, on the other hand, is more preference driven and captures compulsive and affective thoughts and feelings intrinsic to an activity that are not elicited by a reference to unmet goals (e.g., "touching products can be fun" or "when browsing in stores, I like to touch lots of products"). Thus, the instrumental dimension is more relevant to specific product purchase occasions, whereas the autotelic dimension captures individuals' general liking for haptic input from products regardless of whether or not they face an immediate purchase goal.

Each of the two dimensions of NFT (instrumental and autotelic) is composed of six separate items, and Peck and Childers (2003b) suggest, based on the underlying theory, that researchers could employ either the composite NFT scale or one of the two subscales. Previous work in marketing has focused on both the instrumental (Citrin et al. 2003) and autotelic dimensions (Peck and Wiggins 2006; see the appendix) of NFT. In several studies reported by Peck and Wiggins (2006), for example, participants report their liking of communications (e.g., of a promotional pamphlet) and willingness to donate money or to become a member of an organization after reading a communication that did or did not have a haptic element attached to it (such as tree bark on a pamphlet for an arboretum). Across several studies, they found that for high (but not low) autotelics, a communication with (vs. without) a positively valenced touch element generally enhanced persuasion.

As in Peck and Wiggins (2006), the current research focuses on the autotelic dimension of NFT, as our primary interest is in understanding the effect of haptic input on consumers' mental processing, not necessarily in the context of an immediate purchase goal. In contrast to prior research, however, the focus here is on nondiagnostic haptic input, with a particular focus on the implications of negatively (vs. positively) valenced cues. Also, the nondiagnostic haptic cues in our research are a natural part of the product-consumption experience, such as the haptic characteristic of the cup or bottle in which water is served, which represents a comparatively subtle manipulation of haptic input compared to prior research (Peck and Wiggins 2006) in which the haptic cue was extraneous to the core consumption experience. Also, in contrast to prior research, we propose here that the impact of nondiagnostic haptic cues on consumers will be moderated by haptic orientation, such that the less haptically oriented individuals will be more likely to exhibit the impact of such cues on product evaluations. The conceptual framework that follows outlines the mental-processing differences between high and low autotelics that provide the rationale for these expectations. 


\section{CONCEPTUAL DEVELOPMENT}

The conceptual framework developed here is based on two related theories: the two-stage model of cognition (Peracchio and Luna 2006; Raghubir and Krishna 1996) and the information-reduction hypothesis (Haider and Frensch 1996). The two-stage model of cognition suggests that, in arriving at product judgments, individuals will engage in a preliminary stage of automatic processing that is followed by a more deliberative, controlled processing stage. In the current context, an automatic judgment would first be formed in which the nondiagnostic haptic input (e.g., firmness of container) may affect product judgment (e.g., of the water). Then, in the second stage of processing, a morecontrolled effort would be undertaken, during which the decision maker, if sufficiently knowledgeable and able, would realize that the haptic input is nondiagnostic in nature and should thus be discounted, given less weight, or entirely ignored in the product judgment.

The information-reduction hypothesis explains how highand low-autotelic individuals would differ in terms of this two-stage process. Specifically, this theory suggests that a difference would emerge in the second, or controlled, stage of processing due to differences in prior experience. Information-reduction theory suggests that repeated practice of a task improves both speed and quality of performance, with this relationship evident across a variety of cognitive tasks (Anderson 1982, 1987; Lassaline and Logan 1993; Logan and Etherton 1994; Logan and Klapp 1991). More recently, Haider and Frensch (1996) showed that changes in the speed and quality of performance are due in part to a reduction in the amount of task information that is processed. Thus, individuals learn, with practice, to become more selective in their use of information when making judgments. Increased practice thereby enables the decision maker to better distinguish between task-relevant versus task-redundant information in this second, more-controlled stage of processing. As a result, more-practiced individuals limit their processing to only task-relevant information in the second stage.

Peck and Childers (2003a) have shown that high (vs. low) NFT individuals are more likely to touch objects, are more adept at using touch to gather information, and are likely to form richer mental product representations that include haptic properties. They suggest that such haptically oriented individuals have higher chronic accessibility to stored haptic information while using less of their cognitive-processing capacity. In addition, their richer mental representation of haptic-related information allows them to recognize more easily when haptic information is diagnostic for the task. We propose that high autotelics will process more haptic information overall than will low autotelics. However, because of their lower need of processing capacity for haptic information, and their greater ability to assess the diagnosticity of haptic input, high autotelics will discount the haptic input that is nondiagnostic to the task and focus their evaluations more on information that is diagnostic to the task. In contrast, since low autotelics are less practiced in processing haptic information, they expend greater resources to retrieve haptic-rel- evant information from memory and thus have less cognitive capacity available to focus on other information. Also, they will not recognize as easily when the haptic information is diagnostic. As such, low autotelics will be more influenced by nondiagnostic haptic information.

Put in simpler terms, people who inherently like to touch and feel objects do so very often (compared to people who do not care as much about touching objects). Over time, they develop an expertise in understanding when touch is diagnostic to a task and when it is not; that is, they know when the touch of a product is related to the inherent product quality and when it is not. Thus, for example, they would realize that the haptic qualities of a sweater are likely to affect the goodness of the sweater. As such, product evaluations of these people would be less affected by semantic connotations of haptics. Thus, while high autotelics might like touching objects overall compared to low autotelics, they are less likely to be "misled" about product quality created by differences in nondiagnostic haptic input.

Based on the preceding arguments we propose the following overarching hypothesis: The product judgments of low, but not high, autotelics will be significantly affected by low-quality nondiagnostic haptic cues. This overarching hypothesis is further broken into two more testable hypotheses:

H1: The product judgments of low (but not high) autotelics will be lower for products with lower (vs. higher) quality nondiagnostic haptic cues.

H2: The product judgments of low (but not high) autotelics will be significantly lower after touching (vs. not) a product with a low-quality nondiagnostic haptic cue.

Recall that we have argued that while high autotelics derive more pleasure from touching, they are simultaneously more consciously aware of haptic cues and their effects on judgment. The product judgments of low autotelics should thus be affected by low-quality nondiagnostic haptic cues, whereas those of high autotelics should not. Note that our explanation depends on the differential impact of low-quality nondiagnostic haptic cues (whereas the overall level of pleasure from touching can be greater for high autotelics). We call this the diagnosticity-based explanation.

An alternative explanation for hypotheses 1 and 2 could be offered. One could argue that high autotelics love touching products. As such, they get more pleasure from the sensations associated with touching products than low autotelics do. This might imply that they get equal pleasure from the sensations associated with touching any product (whether diagnostic or not, and whether it is of low or high haptic quality). In addition, high autotelics can also imagine the pleasurable feeling they will get from touching a product even if they can only see it (and not touch it). On the other hand, low autotelics do not get the same pleasurable feeling from touching products and are more affected by the quality 
of the haptic cue even if it is nondiagnostic; thus, semantic implications of haptics - that a good product will have good haptics and a bad product will have bad haptics-will influence low autotelics. As such, there will be no effect of high- versus low-quality nondiagnostic haptic input for high autotelics, but there will be for low autotelics (hypothesis 2). Also, since high autotelics can imagine the pleasure they will get from touching an object if they can see it, there will be no difference in product judgment for high autotelics in "touch" versus "no touch" conditions. However, there will be a difference for low autotelics (hypothesis 1). Note that this alternate explanation relies on high autotelics getting equal pleasure from high- versus low-quality haptic cues. We call this the pleasure-based explanation.

We next present an overview of four studies designed to test hypotheses 1 and 2 and also test whether the diagnosticity-based or the pleasure-based explanation is more consistent with our results.

\section{OVERVIEW OF STUDIES}

We conducted four studies. The first and third studies test whether hypotheses 1 and 2 hold; that is, they test whether low-but not high - autotelic consumers tend to incorporate nondiagnostic haptic cue information into their product evaluations. The second and third studies are designed to test support (or not) for the pleasure-based alternative explanation for our hypotheses. The fourth study tests more directly our explanation. It utilizes an alternative dependent measure in the form of thought protocols to understand better the process mechanisms of our explanation and our results in earlier studies. Participants in studies 1,2 , and 4 received actual sensorial input; that is, the studies involved touching product containers. Study 3 used written descriptions of haptic qualities as opposed to sensorial input. In all studies, the experimenter was blind to the hypotheses. Studies 1 and 2 used students from a large Asian metropolitan area, whereas studies 3 and 4 used students from a midwestern town.

We chose mineral water as the target product category in all studies. Mineral water is a product category with taste differences that can be distinguished; however, the distinctions are typically subtle, such that nondiagnostic haptic cues could potentially affect consumer perceptions and evaluations. Of the four material properties that are likely to encourage product touch-namely, texture, hardness, temperature, and weight (Peck and Childers 2003a; Lederman and Klatzky 1987) — we investigated the hardness attribute. We thus chose firmness or flimsiness of the cups and bottles containing mineral water as the haptic input in all of the studies.

\section{Pretest for Studies}

We conducted a pretest among 210 undergraduates to determine the types of cups to be used in the studies that involved touching. The haptic stimuli consisted of cups that differed in firmness/flimsiness but were otherwise visually identical. They were clear plastic cups of the same size and shape. They were both transparent and had no designs, ridges, or markings of any sort. As such, the only key difference between the cups was the degree of firmness. The participants were asked to judge the two cups on quality. Specifically, they were asked, "please evaluate the quality of the cup in which the water was served on the following scale" (the scale went from $1=$ low-quality cup to $9=$ high-quality cup). Since nothing varied between the cups besides the firmness, the difference in quality perception can be attributed to haptics. The test was done between subjects so that each participant evaluated either the firm or the flimsy cup. The perceived quality of the firm cup $(M=5.78)$ was significantly greater than that of the flimsy cup $(M=4.90$; $F(1,206)=10.24, p<.005)$. In the pretest, we also had participants fill out the autotelic dimension of the Peck and Childers (2003a, 2003b) NFT scale. If we do a median split of the participants on the autotelic scale to classify half of them as high autotelic and the other half as low autotelic (median $=5.60$ ), then the results do not change; that is, both high and low autotelics find the firm cup to be of better quality than the flimsy cup ( $p$ 's $<.05$ ), and the interaction of autotelic (high vs. low) and cup (firm vs. flimsy) is not significant $(F(1,206)=.39, p>.50)$.

\section{STUDY 1: DOES NONDIAGNOSTIC HAPTIC INPUT AFFECT JUDGMENTS ONLY OF LOW AUTOTELICS?}

Study 1 consisted of a taste test of mineral water. The task for participants was to evaluate the quality of a single, unbranded water sample. In this study we manipulated haptic input by varying whether or not participants were permitted to touch the product container, a plastic cup.

All participants were served the same mineral-water product in a cup that possessed a negatively valenced nondiagnostic haptic quality (i.e., a flimsy cup). Half the participants were allowed to feel the cup in which the mineral water was served, while the other half were not. Our hypothesis was that only low autotelics would exhibit lowerquality evaluations of the water when permitted to feel the flimsy cup in which it was served. This would occur because low autotelics would lack the level of conscious awareness of the high autotelics regarding the effect of haptic cues on their evaluations and would be less likely to correct for it. Thus, low autotelics would be less able to correct for the nondiagnostic haptic-cue input during the second, controlled stage of processing.

\section{Design}

Participants were 180 undergraduate non-business students who were offered a candy bar for participation. The design was a 2 (haptic orientation; high vs. low autotelic) $\times 2$ (haptic input; feel, do not feel flimsy cup) full factorial, between-subjects design. As stated earlier, the autotelic dimension of NFT, which relates to touch as an end in itself and corresponds to the sensory aspect of touch (Peck and Childers 2003a), was expected to be the more relevant di- 
TABLE 1

STUDY 1: PRODUCT QUALITY RATINGS

\begin{tabular}{lcccc}
\hline \hline Measure & Haptic orientation & $\begin{array}{c}\text { Do not feel } \\
\text { flimsy cup }\end{array}$ & $\begin{array}{c}\text { Feel } \\
\text { flimsy cup }\end{array}$ & p-value \\
\hline $\begin{array}{l}\text { Product quality } \\
\text { Product quality }\end{array}$ & Low autotelics & 5.57 & 4.93 & .017 \\
\hline
\end{tabular}

mension for our purposes. A median split on the mean of the six items of the autotelic dimension of the Peck and Childers (2003a, 2003b) NFT scale was used to categorize the participants as either high or low on the autotelic dimension of haptic orientation (median $=5.50$ on a ninepoint scale).

Haptic input was manipulated by allowing half the participants to feel and hold the cup, with the others not permitted to do so. Only a single type of cup was used to serve the water-the flimsy cup, which received a mean rating of 4.03 on a nine-point quality scale, putting it in the negativequality domain (i.e., providing negatively valenced haptic input). Thus, if a cup effect emerges, it should be in a negative direction in terms of the effect on evaluations.

\section{Method}

Participants, one at a time, took part in a mineral-water taste test. They were recruited at a university cafeteria and led to a room with a table. The experimenter was seated behind the table, and participants were asked to sit in front of it. The experimenter had a pitcher, which always contained the same water mixture (one can of Sprite to 6 liters of tap water) on the table, filled to the same point, before the participant entered the room. The experimenter stated, "Hello. We would like you to take part in a taste test of a new mineral water that may be introduced." The participant was then told, "This taste test requires that you taste the water through a straw. Is that all right?" All participants freely agreed to the conditions of the taste test. Each participant read a product description that described the water in terms of its vitamin and mineral content and then evaluated just one water sample.

We wanted to limit the haptic input to that which was not instrumental (i.e., diagnostic) to the judgment. Thus, we wanted to assess the effect of the haptic quality of the cup and not the taste (or feel) of the lip of the cup, which could arguably affect the perceived taste of the water. Hence, in all conditions, participants were asked to consume the water through a straw. As such, the feel of the container in the hand was the only haptic characteristic that was manipulated and that could potentially affect consumer evaluations.

Once the participant was prepared (with straw), the experimenter randomly chose a cup from behind the table (invisible to the participant), placed it on the table, poured the water into the cup, and placed the cup in front of the participant for tasting. The experimenter filled the container to the same level and put the straw into the cup for all participants.
At this point, the experimenter told the participant, "okay, please drink the water given to you in small sips through the straw." In the conditions with haptic input, participants were told, "okay, please hold the cup and drink the water given to you in small sips through the straw." The participant was then asked a set of questions about the quality of the water, knowledge of water, haptic orientation, and demographics.

\section{Results}

Immediately after tasting, participants rated the mineral water in terms of its quality (one-to-nine scale anchored at "very low/very high quality"). An ANOVA was conducted on this measure as a function of the two independent variables (haptic orientation and haptic input). We initially included gender, self-reported knowledge of mineral water (one-to-nine scale anchored at "not at all/very knowledgeable"), and age as covariates that we had measured, although only gender approached significance $(p<.065)$ and was retained in the model. (Note that as is done here, all subsequent analyses include only covariates that emerged significant.) Males provided directionally higher quality ratings. There was a significant main effect of haptic orientation $\left(F(1,175)=4.24, p<.05, \eta^{2}=.024\right)$, with high autotelics providing a higher mean quality evaluation overall $(M$ (high autotelic) $=5.63$ vs. $M$ (low autotelic $)=5.25)$. But this result is qualified by a significant interaction of haptic orientation and haptic input $(F(1,175)=4.50, p<.05$, $\left.\eta^{2}=.025\right)$, which showed that the low-quality haptic input (i.e., feeling the flimsy cup) elicited more-negative evaluations only among the low autotelics ( $M$ (haptic input) $=$ 4.93 vs. $M$ (no haptic input) $=5.57 ; F(1,175)=5.80$, $p<.05)$, as predicted. The low-quality haptic input had no effect on the high autotelics' evaluations of water quality ( $M$ (haptic input) $=5.69$ vs. $M$ (no haptic input) $=5.56$; $F(1,175)=.29, p>.5$; see table 1$)$. Since the product served to all participants was identical, this result reflects the downward effect of the negatively valenced nondiagnostic haptic cue on low autotelics' product evaluations.

Study 1 shows that touching (vs. not) a flimsy cup (i.e., a low-quality haptic input) in which water is served will affect quality perceptions for the water among low autotelics but not among high autotelics. This is consistent with hypothesis 2 that the product judgments of low (but not high) autotelics will be significantly lower after touching (vs. not) a product with a low-quality nondiagnostic haptic cue. 


\section{STUDY 2: DO HIGH AUTOTELICS OBTAIN EQUAL PLEASURE FROM TOUCHING FIRM AND FLIMSY CUPS?}

Study 2 was conducted to test the alternative pleasurebased explanation that could account for our pattern of results. The first, or diagnosticity-based explanation, contends that high (vs. low) autotelics receive more pleasure from touching objects, tend to touch them more, and are more consciously aware of the potential effect of haptic cues on product judgment. As a result, they are more capable of adjusting for such cues in their product judgments when they are nondiagnostic in nature, compared to low autotelics. The product judgments of low autotelics thus should be affected by nondiagnostic haptic cues, whereas those of high autotelics should not.

The alternate pleasure-based explanation, which is tested in this study, suggests that since high autotelics enjoy touching products so much, they obtain equal pleasure from touching any product-whether diagnostic or not in terms of product evaluation, and regardless of whether it has lowor high-quality haptic cues. Conversely, low autotelics do not obtain this level of pleasure from touching products and are therefore more affected by the quality of haptic cues even though they are nondiagnostic for product evaluation. The semantic implications of haptic cues-that a good product will have good haptics and a bad product will have bad haptics-will influence low autotelics.

A critical assumption of the pleasure-based explanation is that high autotelics get equal pleasure from the sensations associated with touching firm and flimsy containers. In this experiment, we directly test this assumption. To measure pleasure from the sensations associated with touching the firm versus flimsy cups, we asked participants the question, "how much did you like the feel of the cup the water was in?" (on a scale of $1=$ did not like at all to $10=$ liked very much). This was deemed a more appropriate question than one worded, "how much pleasure did you get from holding the firm cup?" which may have been considered odd by participants. We also did not want to use an adapted subset of the autotelic scale since then our results could be confounded with responses on the autotelic scale.

An additional aspect of this experiment is to focus on the effect of touch alone, without any visual input. Thus, we have two sensory conditions - one in which participants are blindfolded and can only touch the cup, and one where they are not blindfolded and can both touch and see the cup. The blindfolded condition was included so that we could obtain a measure of pleasure from the pure haptic sensation for high versus low autotelics. The normal (see and touch) condition was included, since that is how participants experienced stimuli in studies 1 and 3, and also how they experience stimuli in the real world.

\section{Design}

Participants were 271 undergraduate students who completed the experiment as part of a subject pool. The design was a 2 (haptic quality, firm or flimsy cup) $\times 2$ (sensory input, could touch and see the glass or could touch but not see the glass) $\times 2$ (haptic orientation, high vs. low autotelic) full-factorial, between-subjects design. Participants' haptic orientation was measured using the NFT scale, and we performed a median split to categorize participants as high or low autotelic based on the autotelic dimension of the scale (the median on the nine-point scale was 6.00).

\section{Method}

Participants were led into a room one at a time. In the room they were asked to sit in front of a table. The experimenter was behind the table. The table had a cup on it that was three-fourths full of water. Participants were asked to pick up the cup and feel it. For the blindfolded condition, the participants were blindfolded before they entered the room. For these participants, the experimenter stated, "This test requires that I cover your eyes with a blindfold. Is that all right?" During the test, the experimenter helped these participants find the cup. When ready, participants were told, "okay, please hold the cup and get a feel of it."

All participants were asked a set of questions about the cup, mineral water in general, and demographics, and were also administered the NFT scale. All participants answered the questions after the cup was removed (blindfolded participants did this after the cup was taken away from sight and the blindfold was removed).

\section{Results}

Participants were asked, "how much did you like the feel of the cup the water was in?" on a scale of $1=$ did not like at all to $10=$ liked very much. We conducted an ANOVA on their response to this question as the dependent variable, and haptic quality (firm vs. flimsy cup), visual input (blindfolded or not), and haptic orientation (high vs. low autotelic) as the independent variables. None of the covariates were significant and were thus excluded from the analysis.

There was a significant main effect of haptic quality $\left(F(1,263)=9.11, p<.005, \eta^{2}=.03\right)$, with participants liking the feel of the cup more if it was firm $(M=6.00)$ rather than flimsy $(M=5.15)$. There was also a significant effect of haptic orientation $\left(F(1,263)=6.81, p<.01, \eta^{2}=03\right.$; see table 2 for means), with high autotelics liking the feel of the cups more overall than low autotelics $(M$ (high) $=5.94$ vs. $M$ (low) $=5.21)$. Contrary to the pleasure-based explanation, we find that both high and low autotelics like the feel of the firm cup more than that of the flimsy cup: ( $M$ (firm) $=6.40$ vs. $M$ (flimsy) $=5.48 ; p<.05)$ for high autotelics, and $(M$ (firm) $=5.59$ vs. $M$ (flimsy) $=4.83 ; p<.05)$ for low autotelics. Thus, the crucial assumption for the alternative pleasure-based explanation is not supported.

This study shows that both high and low autotelics find the "feel" of the firm cup better than that of the flimsy cup. As such, we believe that the alternate pleasure-based explanation is less likely to justify our results. 
TABLE 2

STUDY 2: MEAN LIKING OF FEEL OF CUP

\begin{tabular}{llccc}
\hline \hline $\begin{array}{l}\text { Haptic } \\
\text { orientation }\end{array}$ & $\begin{array}{l}\text { Blindfold } \\
\text { condition }\end{array}$ & $\begin{array}{c}\text { Firm } \\
\text { cup }\end{array}$ & $\begin{array}{c}\text { Flimsy } \\
\text { cup }\end{array}$ & $p$-value \\
\hline Low autotelics & Not see & 6.05 & 5.00 & .119 \\
Low autotelics & See & 5.14 & 4.66 & .158 \\
$\quad$ Total & & 5.59 & 4.83 & .043 \\
High autotelics & Not see & 6.37 & 5.73 & .213 \\
High autotelics & See & 6.44 & 5.23 & .064 \\
$\quad$ Total & & 6.40 & 5.48 & .027 \\
\hline
\end{tabular}

\section{STUDY 3: DO NONDIAGNOSTIC HAPTIC CUES ALSO EMERGE WHEN THE HAPTIC CUES ARE ONLY VERBALLY COMMUNICATED?}

Study 3 tests the robustness of study 1 results by changing the stimuli from actual haptic input to a written description of haptic input. Also, we use an alternate dependent variable, namely "willingness to pay," to enhance the generalizability of results. Further, while the haptic input in study 1 was a natural part of the product-consumption experience, it was not a part of the product itself (the water was poured into a cup and thus not in the bottle). In this study, the haptic cue is part of the product itself (we look at the haptic quality of the bottle containing the water). We see whether the pattern of study 1 results - that only low autotelics tend to be affected by nondiagnostic haptic-holds when the packaging stimuli are communicated only verbally (vs. being sensorially experienced through touch). Study 3 also tests whether the experiment results are consistent with the diagnosticity-based explanation.

\section{Design}

Participants were 277 undergraduate students who completed the experimental task as part of a participant pool. The design was a 2 (haptic orientation, high vs. low autotelic) $\times 2$ (haptic cue description, firm vs. flimsy bottle) full factorial between subject. A median split (median = 5.95 on a nine-point scale) on the mean of the six items of the autotelic dimension of the Peck and Childers (2003a, $2003 \mathrm{~b})$ NFT scale was used to categorize the participants as either high or low autotelic. The nondiagnostic haptic cue in this study consisted of how the bottle in which a new mineral water will be sold is described (as either firmer/ sturdier or thinner/more flimsy).

\section{Method}

All participants read the following:

A beverage firm has developed a new bottled water which will soon be introduced in your market. Please read the description of the product below and then answer the questions that follow.
Participants then read the following product description:

\begin{abstract}
This sparkling mineral water originates from a spring that flows naturally to the earth's surface. The water contains minerals your body needs such as calcium, magnesium, and potassium. It also contains just a touch of fruit juice for added flavor and vitamins. A series of independent taste tests confirmed its superiority to ordinary tap water and to some of the major competitors in the bottled water category. The tests also revealed that the bottle itself feels thinner [firmer] and more flimsy [sturdier] than most other brands.
\end{abstract}

Participants were then asked how much they would be willing to pay for this water. They were informed that a similar-sized bottle of water of other brands costs anywhere from $\$ 1.50$ to $\$ 2.00$. They were then asked how much they liked the description of the bottle in which the water would be sold and how knowledgeable they were about bottled water compared to their peers. They also filled out the autotelic dimension of the NFT scale and other demographic items. The key dependent measure in this study was price willing to pay. Because this was an open-ended response, there was considerable variation in responses, with several extreme outliers. We eliminated 14 such extreme prices (e.g., $\$ .00$, which was more than three standard deviations from the mean), resulting in a final sample of 263 participants.

\section{Results}

We conducted an ANOVA on the price consumers were willing to pay for the new bottled water as a function of the bottle description (firm vs. flimsy), haptic orientation (high vs. low autotelic), and the covariates of age, gender, and knowledge. Since none of the covariates were significant, they were omitted from the model. The only significant effect on price willing to pay was the interaction of bottle description and haptic orientation $\left(F(1,259)=4.61, p<.05, \eta^{2}=\right.$ .017). Inspection of the means showed that low autotelics were willing to pay more for the bottled mineral water in the firmer bottle ( $\$ 1.72$ firm vs. $\$ 1.57$ flimsy; $p<.01$ ), but that high autotelics' willingness to pay was not altered by bottle firmness (\$1.62 firm vs. \$1.64 flimsy; $p>.7$; see table 3). 
TABLE 3

STUDY 3: PRICE WILLING TO PAY

\begin{tabular}{llcc}
\hline \hline Measure & $\begin{array}{c}\text { Haptic } \\
\text { orientation }\end{array}$ & $\begin{array}{c}\text { Firm bottle } \\
\text { description }\end{array}$ & $\begin{array}{c}\text { Flimsy bottle } \\
\text { description }\end{array}$ \\
\hline $\begin{array}{l}\text { Price willing to pay } \\
\text { Price willing to pay }\end{array}$ & Low autotelics & $\$ 1.72$ & $\$ 1.57$ \\
\hline
\end{tabular}

Study 3 shows that imagining drinking water from a firm (vs. flimsy) bottle of water will affect willingness to pay among low autotelics but not among high autotelics. This is consistent with study 1 results and with hypothesis 1 that the product judgments of low (but not high) autotelics will be higher for products with higher (vs. lower) quality nondiagnostic haptic cues. Together, studies 1 and 3 also support our basic hypothesis that the product judgments of low, but not high, autotelics will be significantly affected by nondiagnostic haptic cues.

\section{STUDY 4: CAN NONDIAGNOSTIC HAPTIC CUES AFFECT THOUGHTS GENERATED ABOUT THE PRODUCT?}

In study 4, we test for our diagnosticity-based explanation more directly. Thus, we try to understand better the process mechanisms at work for the effect of haptic cues on product judgment. We use a different dependent measure (thoughts about the water and the tasting context) and again manipulate haptic quality, using firm and flimsy cups. We design a scenario to induce negative thoughts for the product (water in the cup). Our theory suggests that high autotelics should realize that the product (water) and the cup are separate entities and that the cup does not affect the water quality. Therefore, they should have the same proportion of negative thoughts about the water, irrespective of the cup in which it is served. However, low autotelics should be affected by the cup such that they have a lower proportion of negative thoughts about the water when it is served in a firm cup.

In this study, we also make half the participants aware of the cup as a separate entity at the start of the experiment, whereas we do not do this for the other half. Since high autotelics are already aware of the nondiagnostic nature of the cup, making them aware of the cup as a separate entity should not affect their product evaluation (both firm and flimsy cups should still be associated with an equal number of negative thoughts about the water). We expected that making low autotelics aware of the cup as a separate entity might reduce the processing differences between high and low autotelics, alerting low autotelics to the nondiagnostic nature of the cup effect and thus allowing them to correct for it, as high autotelics do.

\section{Design}

Participants were 225 undergraduate business students who took part in the experiment to fulfill a subject-pool requirement. The study consisted of a 2 (haptic quality: firm vs. flimsy cup) $\times 2$ (explicit cup awareness at the start of the experiment: yes, no) $\times 2$ (haptic orientation: high vs. low autotelic) full factorial. As before, we measured participants' haptic orientation using the NFT scale and classified them as high or low on the basis of a median split on the autotelic dimension of the scale. Explicit cup awareness was manipulated by informing half the participants that the firm conducting the test of mineral water was also interested in the participant's opinion of the cup in which the mineral water was served.

\section{Method}

In this study, students' desks had been individually prepared with a cup of mineral water (the same formula used in the previous studies) in either a firm or flimsy cup (the same cups used in the previous studies). Upon sitting at their seats, students opened a booklet that provided them with the following instructions:

\begin{abstract}
We would like you to take part in the test of a new mineral water that an airline is thinking of serving on its flights. They will be charging for the water in flight. [The airline is also interested in your opinion of the cups they use to serve the water.] The mineral water is in front of you. Note that the cup has a straw in it. Here is what we want you to do. Please follow these instructions exactly. Please pick up the cup and then take five small sips of the water through the straw and taste it carefully.
\end{abstract}

After sipping the water, each participant was asked to "write down everything that went through your mind while drinking the water (whether or not you believe it is relevant)." Thoughts listed by participants served as the main dependent variable for the study (details provided later). They also completed the NFT scale and a self-reported knowledge of mineral water scale (one-to-nine scale anchored at "not at all/very knowledgeable"). Finally, they provided their age and gender.

Note that our informing participants that "the airline will be charging for the mineral water" was done to induce negative thoughts about the water. While it was not necessary to focus on a negatively valenced situation in this study, we did so as a design choice. In study 1, we focused on touching a flimsy cup (or not), a negatively valenced haptic cue. In studies 2 and 3 we had both flimsy and firm cups. In study 4 , once again, we focused on a negatively valenced situation. 


\section{Results}

Valence of Thoughts. Participants' thoughts were coded, by two independent coders, as positive (e.g., "tastes pretty good"), negative (e.g., "this is not very satisfying"), or neutral (e.g., "carbonated") in valence. The few inconsistencies in coding $(<5 \%)$ were discussed and agreed upon. On average, respondents listed .35 positive thoughts, .75 negative thoughts, and 2.2 neutral thoughts. The large number of neutral thoughts is consistent with mineral water not being a high-involvement product for most consumers- that is, consumers not having strong emotional reactions to it. However, among the nonneutral thoughts, there were more negative than positive thoughts listed, suggesting that our manipulation for inducing negative thoughts worked. Since the number of thoughts varies greatly by participant (the range is one to nine), we use the number of negatively valenced as a proportion of all thoughts listed by a participant as our dependent variable.

An ANOVA on the proportion of negative thoughts as a function of haptic quality (firm vs. flimsy cup), cup awareness (yes, no), and haptic orientation (high, low autotelic) was conducted. Age was the only covariate directionally $(p<.10)$ significant and thus was retained in the model. Older participants exhibited a directionally higher proportion of negative thoughts. The only significant effect was the interaction of haptic quality with haptic orientation $\left(F(1,216)=3.92, p<.05, \eta^{2}=.018\right)$. Inspection of the means showed that tasting the mineral water from a firm cup reduced the proportion of negative thoughts significantly among low autotelics $(M($ firm $)=.183$ vs. $M($ flimsy $)=$ $.309 ; p<.05)$ but not among high autotelics $(M($ firm $)=$ .257 vs. $M$ (flimsy) $=.199 ; p>.3$; see table 4$)$. It is interesting to note that making participants aware of the cup as a separate entity for evaluation did not affect low autotelics' judgments about the water itself, as we expected it might. It would appear that to correct for low autotelics' reliance on nondiagnostic haptic cues, an even more salient manipulation is required.

Content of Thoughts. We also conducted a content analysis of consumer mentions of various aspects of the water and tasting task. We have proposed that high autotelics process more information about the haptic qualities of objects. As such, they should mention the cup more often in their thought listing. This, in turn, should make high autotelics more able to correct for such influences in the evaluation task.

We coded participants' mentions of how the water tasted (e.g., it tasted sweet, fruity, or flat) and other aspects of the water (e.g., it was cold or warm, it was carbonated, or how it smelled or felt in the mouth). We also coded for mentions of the cup itself. Finally, we coded for mentions of differences from expectations and also for mentions regarding ability to judge the water. Participants' mentions of each of these items were coded by two independent coders, and the few inconsistencies in coding $(<10 \%)$ were discussed and agreed upon. Note that the total number of mentions of content exceeds the total number of valenced thoughts because consumers often mentioned several aspects of the water (e.g., taste, temperature, or appearance) in a single thought (e.g., "do not like the fruity aftertaste"). While this is a single (negatively valenced) thought, it is counted as mentions of several different types (i.e., having a fruity flavor, having an aftertaste, and tasting bad).

The largest proportion of mentions was related to how the water tasted and to aspects of the water itself ( $71 \%$ of mentions, or 3.04 mentions on average), followed by the set of mentions concerning expectations (15\%, or .63 mentions on average). The next-highest incidence was for mentions regarding the ability to judge the water $(4 \%$, or .17 mentions on average) and for mentions of the cup itself (3\% of mentions, or .12 mentions on average). Remember that in the awareness condition, participants were told that the airline was also interested in their opinion of the cup. As such, we would expect both high and low autotelics to mention the cup more often when they were made aware of it. Analyses of the types of mentions showed that only those related to the cup resulted in significant results, and we limit our discussion to these.

We conducted an ANOVA on mentions of the cup as a function of haptic quality (firm, flimsy cup), cup awareness (yes, no), and haptic orientation (high, low autotelic), and on the covariates. Because none of the covariates were significant, they were dropped from the analysis. The ANOVA on the number of cup-related mentions resulted in two significant main effects: $\left(F(1,217)=4.56, p<.05, \eta^{2}=\right.$ $.021)$ for haptic orientation and $(F(1,217)=4.58, p<.05$, $\left.\eta^{2}=.021\right)$ for cup awareness. Inspection of the means

TABLE 4

STUDY 4: MEAN PROPORTION NEGATIVE THOUGHTS

\begin{tabular}{lllll}
\hline \hline $\begin{array}{l}\text { Cup awareness } \\
\text { condition }\end{array}$ & $\begin{array}{c}\text { Haptic } \\
\text { orientation }\end{array}$ & $\begin{array}{c}\text { Firm } \\
\text { cup }\end{array}$ & $\begin{array}{c}\text { Flimsy } \\
\text { cup }\end{array}$ & $p$-value \\
\hline Aware & Low autotelics & .171 & .285 & .222 \\
Aware & High autotelics & .271 & .197 & .378 \\
Not aware & Low autotelics & .198 & .325 & .152 \\
Not aware & High autotelics & .242 & .203 & .669 \\
Total & Low autotelics & .183 & .309 & .050 \\
Total & High autotelics & .257 & .199 & .357 \\
\hline
\end{tabular}


shows that high autotelics mentioned the cup about twice as many times as did low autotelics $(M=.173$ vs. $M=$ $.069 ; p<.05)$; that is, about 1 in 6 high autotelics versus 1 in 12 low autotelics mentioned the cup. Also, as might be expected, those made explicitly aware of the cup mentioned the cup more often than did those who were not made aware $(M=.173$ vs. $M=.069$, respectively; $p<.05)$. None of the other effects were significant.

These results provide some additional evidence that high autotelics tend to be more consciously aware of the cup in which the water is served and thus should be better able to correct for its influence on their taste evaluations. Low autotelics, in contrast, likely should be less able to mentally correct for the influence of such factors.

Summary of Study. This study shows that high autotelics are more consciously aware of the cup in which water is served. As such, they should be more able to correct for the effect of nondiagnostic haptic cues. This provides further support for the diagnosticity-based explanation for the basic hypothesis that the product judgments of low, but not high, autotelics will be significantly affected by nondiagnostic haptic cues.

Supporters of the pleasure-based explanation could argue that since high autotelics get equal pleasure from touching the firm and flimsy cups, they have the same proportion of negative thoughts for the two. However, the results from study 2 (that high autotelics do not get equal pleasure from touching firm and flimsy cups) suggest that this argument is less sustainable. One could also argue that high autotelics enjoy and are thus more attentive to haptic cues, of which the cup is one. Therefore, it follows by definition that they should be more likely to mention the haptic cue (the cup). However, this would still not explain why low autotelics have more negative thoughts with a flimsy versus firm cup while high autotelics do not. Regardless, future research should explore further our diagnosticity-based explanation.

\section{GENERAL DISCUSSION}

Prior research on consumer haptics has established that those who like to touch products are more influenced by the sense of touch when they should be, that is, when the haptic input is diagnostic to the task at hand (Peck and Childers 2003a, 2003b). The results of the present research suggest, however, that haptically oriented individuals will not always be more influenced by touch-related input compared to those who are less haptically oriented. Instead, we find that those who like to touch are less influenced by touch-related input when they should indeed be less influenced, that is, in the context of nondiagnostic haptic cues. Thus, the current research implies some boundary conditions to prior research findings.

We found that the nondiagnostic haptic qualities of a product package or serving container can affect how a product is evaluated; that is, such cues can indeed have an effect on product evaluation. We discovered that this process of perceptual transfer is most likely to occur for haptically non- expert consumers, or those for whom touching products is not particularly motivating. Studies 1,3 , and 4 show that nondiagnostic haptic cues tended to affect the perceptions and evaluations only of low autotelic consumers, that is, those with a lower need for touch.

We obtained this pattern of results using different dependent measures (product judgments, price willing to pay, thoughts), as a function of both actual haptic cue input (feeling a product container) and descriptive haptic cue input (reading about a product container), and when the haptic cue was part of the product itself (water in a bottle) versus not (water poured into a disposable cup). Low autotelics would thus appear to be more vulnerable to such irrelevant cues, as they were more likely to evaluate a mineral water more negatively when touching a flimsy disposable cup (vs. a firm cup or vs. not touching the cup), and willing to pay a higher price for bottled water described as being sold in a firm (vs. flimsy) bottle. The studies give credence to our basic hypothesis that the product judgments of low, but not high, autotelics will be significantly affected by nondiagnostic haptic cues. The results are also consistent with our two more testable hypotheses: hypothesis 1 , which proposes that the product judgments of low (but not high) autotelics will be lower for products with lower (vs. higher) quality nondiagnostic haptic cues, and hypothesis 2, which suggests that the product judgments of low (but not high) autotelics will be significantly lower after touching (vs. not) a product with a low-quality nondiagnostic haptic cue.

Two alternate explanations for hypotheses 1 and 2 exist: the diagnosticity-based explanation and the pleasure-based explanation. The data obtained in studies 1 and 3 support the diagnosticity-based explanation, which suggests that high autotelics realize when haptic cues are nondiagnostic and adjust for this in their product evaluation, whereas low autotelics cannot. We propose that this holds because high autotelics, who enjoy touching products more than do low autotelics and hence have acquired greater experience with touching products, are better able to discern when touch is diagnostic for product-evaluation tasks. The alternate pleasure-based explanation suggests that high autotelics get equal pleasure from both firm and flimsy cups and hence the semantic connotations of haptic cues (that the firm cup implies a better product) do not affect product evaluation. In studies 2 and 3, we provide additional support for the diagnosticity-based explanation.

Both studies 2 and 3 indicate that high and low autotelics alike prefer the feel of firm cups to flimsy cups. Thus, it does not appear to be true that high autotelics obtain equal enjoyment from touching firm and flimsy cups. In study 4, which is designed to induce negative thoughts about the product, we show that the proportion of negative thoughts generated about the product varies by cup quality for low autotelics but not for high autotelics. Both of these studies provide additional support for our explanation, although we do not claim that they "prove" our explanation or that they "disprove" the alternate explanation.

Study 3 is based on a verbal description and hence an 
"imagined touch." Our results from study 3 are consistent with those from studies 1 and 4, in which the stimuli are actually touched. Similar consistent results for real and imagined products have also been obtained by Peck and Childers (2003b), who showed pictures of the product. Beyond its theoretical contribution to sensory research, the current research has considerable managerial significance. Firms such as McDonald's, Starbucks, and Dunkin' Donuts spend millions of dollars on disposable cups and bottles each year. If such firms try to save on costs by using haptically inferior packaging, this could affect consumers' perceptions of the taste or quality of the beverages they contain. These studies also suggest that if alternate versions of a product (e.g., single malt scotch vs. a blended scotch) are served in different containers at a social function to set them apart, then consumers may (mistakenly) think that the better-quality product will be served in the haptically superior container. The studies also suggest that if lower-price generic products want to be perceived as being just as good as branded products, they may want to reconsider cutting costs via lower-quality packaging.

On the other hand, if firms make thinner containers and emphasize their environmentally friendly (less wasteful) aspects, then the thin haptic may be perceived positively and may be reflected in more-positive product evaluation (the semantic association may now be "thinner is better"). Study 2 furthermore suggests that consumers do not necessarily have to touch a product to be affected by its haptic qualities. Even a verbal description of the haptic qualities in an advertisement, for instance, can affect product evaluation.

Note that NFT is a measurable individual difference (like the need for cognition) and is relatively stable across products and situations. Still, the type of product (one in which haptic attributes are diagnostic or not) or the situation (pointof-purchase [POP] signs in a store encouraging touch) may affect the motivation of an individual to touch and also influence NFT. In this manner, one could manipulate "touch" and "NFT." Thus, in situations where haptic inputs are diagnostic, consumers should be encouraged to touch the product (e.g., through POP displays or product packaging that allows touch); this will increase their NFT and subsequently increase touching. As such, consumers would make better decisions in these scenarios. Future research should also focus on other ways to manipulate NFT to encourage touching and thus better decision making when haptics are diagnostic for the product judgment.

Where haptics are nondiagnostic, low NFTs should be made aware of this fact and thus encouraged not to rely on semantic associations of touch. In other words, where it is important for low autotelics to not be misled by nondiagnostic haptics, they should be informed that the haptics are unimportant. For instance, when choosing medicines, people should focus less on packaging and more on ingredients. Low-price medicines in cheap packaging should try and make this clear on the packet so that low autotelics make the right choice. Similarly, lower-priced brands of mass-consumed food items such as cereal, orange juice, shampoo, and moisturizer should try and focus consumer attention away from haptics and toward the contents.

Our diagnosticity-based explanation needs further research to determine whether the differences between high and low autotelics occur because high autotelics recognize when haptic input is (or is not) diagnostic or because only high autotelics have sufficient resources to adjust for the bias. Also, in study 3, the mineral-water bottle was described as being thin and flimsy. This is clearly not realistic. Hence, the effect of verbal information needs further testing. The findings also indicate the need for much future research on haptics. Additional research is needed to study the effect of positively valenced haptic properties on consumer judgment. For example, research could explore the effect of haptic cues that might be interpreted as positive or negative based on contextual information.

In terms of future research with managerial implications, additional work is required in order to better understand the interplay between brand equity and haptic cue effects. Are haptic cues relied upon to a greater or lesser extent as a function of level of brand equity? Do lesser-known brands, for example, have greater upside potential in terms of evaluation enhancement from the perceptual transfer of haptic cues? There is also a need for a better understanding of the profile of haptically oriented consumers. What other attitudinal, demographic, or behavioral characteristics are associated with haptically oriented consumers, and do they represent an easily identifiable and thus targeted audience? There are, in addition, other dimensions of haptics worth pursuing. Besides the material quality of the object (that we have explored), how does the shape of a package affect haptic feel and thus the perceptual transfer process and product evaluation? For example, do pear-shaped bottles that are easier to hold affect evaluation of the bottle content? Similarly, does the weight of the total object, including packaging, affect evaluation of the core product-will chocolate taste better if the box is heavier, perhaps connoting creamier, denser chocolates? Study 3, which shows that product evaluation can be affected by verbal descriptions of product haptics (without experiencing the product), implies that a sensory cue related to the product can set up expectations for the product. As such, it suggests a whole new domain for future research-how can a sensory cue lead to "expectations" for another sensory cue and for the object as a whole?

The current research also indicates that perceptual transfer may occur within the context of other sensory processes. Future research can explore other domains for this phenomenon-for instance, do package smell or graphics affect product quality evaluations? And how do the sensory processes interact? For example, do bed sheets feel softer to the touch (haptics) if they come in a graphically appealing package (vision)? Our research suggests that a good understanding of the effect of nondiagnostic haptic cues is clearly important for managers for their product and packaging decisions. If the haptic feel of bottles and cups in which drinks are served and/or sold affects brand inferences, taste perceptions, and reservation price, then evidently the 
choice of material for packaging and for dispensing drinks has implications for managerial profits. A dawning comprehension of the importance of this decision has spawned much recent consumer research on haptics. Our hope is to add to this growing body of research by bringing further insight to the effect of the quality of nondiagnostic haptic input and to the moderating effects of individual differences in the use of haptic input.

\section{APPENDIX}

\section{AUTOTELIC NEED-FOR-TOUCH ITEMS (PECK AND CHILDERS 2003B)}

1. When walking through stores, I cannot help touching all kinds of products.

2. Touching products can be fun.

3. When browsing in stores, it is important for me to handle all kinds of products.

4. I like to touch products even if I have no intention of buying them.

5. When browsing in stores, I like to touch lots of products.

6. I find myself touching all kinds of products in stores.

\section{REFERENCES}

Anderson, John R. (1982), “Acquisition of Cognitive Skill,” Psychological Review, 89, 369-406.

- (1987), "Skill Acquisition: Compilation of Weak-Method Problem Solutions," Psychological Review, 94, 192-219.

Argo, Jennifer, Darren Dahl, and Andrea Morales (2006), "Consumer Contamination: How Consumers React to Products Touched by Others," Journal of Marketing, 70 (2), 81-94.

Broniarczyk, Susan M. and Andrew Gershoff (1997), "Meaningless Differentiation Revisited," in Advances in Consumer Research, Vol. 24, ed. Merrie Brucks and Deborah J. MacInnis, Provo, UT: Association for Consumer Research, 223-28.

- (2003), "The Reciprocal Effects of Brand Equity and Trivial Attributes," Journal of Marketing Research, 40 (May), 161-75.

Cacioppo, John T. and Richard E. Petty (1982), "The Need for Cognition," Journal of Personality and Social Psychology, 42, 116-31.

Citrin, Alka, Donald Stem Jr., Eric Spangenberg, and Michael Clark (2003), "Consumer Need for Tactile Input: An Internet Retailing Challenge," Journal of Business Research, 56, 915-22.

Crusco, April H. and Christopher G. Wetzel (1984), "The Midas Touch: The Effects of Interpersonal Touch on Restaurant Tipping," Personality and Social Psychology Bulletin, 10 (December), 512-17.

Haider, Hilde and Peter A. Frensch (1996), "The Role of Information Reduction in Skill Acquisition," Cognitive Psychology, 30 (3), 304-37.
Hornik, Jacob (1992), "Haptic Stimulation and Consumer Response," Journal of Consumer Research, 19 (December), 449-58.

Hornik, Jacob and Shmuel Ellis (1988), "Strategies to Secure Compliance for a Mall Intercept Interview," Public Opinion Quarterly, 52 (4), 539-51.

Jarvis, W. Blair G. and Richard Petty (1996), "The Need to Evaluate," Journal of Personality and Social Psychology, 70 (1), 172-94.

Lassaline, Mary L. and Gordon D. Logan (1993), "Memory-Based Automaticity in the Discrimination of Visual Numerosity," Journal of Experimental Psychology: Learning, Memory and Cognition, 19, 561-81.

Lederman, Susan J. and Roberta L. Klatzky (1987), "Hand Movements: A Window into Haptic Object Recognition," Cognitive Psychology, 19 (July), 342-68.

Logan, Gordon D. and Joseph L. Etherton (1994), "What Is Learned in Automatization? The Role of Attention in Constructing an Instance," Journal of Experimental Psychology: Learning, Memory and Cognition, 20, 1022-50.

Logan, Gordon D. and Stuart T. Klapp (1991), "Automatizing Alphabet Arithmetic. I. Is Extended Practice Necessary to Produce Automaticity?" Journal of Experimental Psychology: Learning, Memory and Cognition, 17, 179-95.

McClelland, David, Richard Koestner, and Joel Weinberger (1989), "How Do Self-Attributed and Implicit Motives Differ?" Psychological Review, 96 (4), 690-702.

McDaniel, Carl and R. C. Baker (1977), "Convenience Food Packaging and the Perception of Product Quality," Journal of Marketing, 41 (4), 57-58.

Meyvis, Tom and Christopher Janiszewski (2002), “Consumers' Beliefs about Product Benefits: The Effect of Obviously Irrelevant Product Information," Journal of Consumer Research, 28, 618-35.

Peck, Joann and Terry L. Childers (2003a), "Individual Differences in Haptic Information Processing: The 'Need for Touch' Scale," Journal of Consumer Research, 30 (December), 430-42.

- (2003b), "To Have and To Hold: The Influence of Haptic Information on Product Judgments," Journal of Marketing, 67 (April), 35-48.

Peck, Joann and Jennifer Wiggins (2006), "It Just Feels Good: Customers' Affective Response to Touch and Its Influence on Persuasion," Journal of Marketing, 70 (4), 56-69.

Peracchio, Laura A. and David Luna (2006), "The Role of ThinSlice Judgments in Consumer Psychology," Journal of Consumer Psychology, 16 (1), 25-32.

Raghubir, Priya and Aradhna Krishna (1996), "As the Crow Flies: Bias in Consumers' Map-Based Distance Judgments," Journal of Consumer Research, 23 (June), 26-39.

Shiv, Baba, Ziv Carmon, and Dan Ariely (2005), "Placebo Effects of Marketing Actions: Consumers May Get What They Pay For," Journal of Marketing Research, 42 (4), 383-93.

Simonson, Itamar, Stephen M. Nowlis, and Yael Simonson (1993), "The Effect of Irrelevant Preference Arguments on Consumer Choice," Journal of Consumer Psychology, 2 (3), 287-306.

van Osselaer, Stijn M. J., Joseph W. Alba, and Puneet Manchanda (2004), "Irrelevant Information and Mediated Intertemporal Choice," Journal of Consumer Psychology, 14 (3), 257-70.

Wolfe, Jeremy M., Keith R. Kluender, and Dennis M. Levi (2006), Sensation and Perception, Sunderland, MA: Sinauer. 